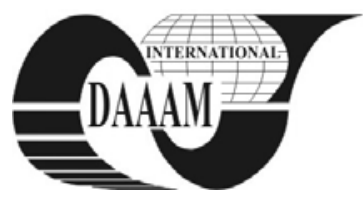

Annals of DAAAM for 2011 \& Proceedings of the 22nd International DAAAM Symposium, Volume 22, No. 1, ISSN 1726-9679 ISBN 978-3-901509-83-4, Editor B. Katalinic, Published by DAAAM International, Vienna, Austria, EU, 2011 Make Harmony between Technology and Nature, and Your Mind will Fly Free as a Bird Annals \& Proceedings of DAAAM International 2011

\title{
NON-CONTACT METHOD OF PART SURFACE SCANNING
}

\section{KYAS, K[amil]; STANEK, M[ichal]; MANAS, M[iroslav]; MANAS, D[avid]; CERNY, J[akub] \& SKROBAK, A[dam]}

Abstract: Reverse engineering is now considered one of technologies for improving the quality of products and manufacturing equipment. It is a technology to provide business benefits in shortening the product development cycle. This paper shows that using two-dimensional laser CNC scanner with appropriate software can give acceptable results as more dimensional laser. Tool Digitalized Shape Editor of Software Catia V5R18 was applied for completing of scanning data at this experiment. These received data should be helpful and advantageous for using of $2 D$ scanners. Ceramic coffee cup was used for the scanning to keep of author's hand writing. Key words: reverse engineering, scanner, cloud of points, scanning, $C A D$

\section{INTRODUCTION}

Engineering is the process of designing, manufacturing, assembling, and maintaining products and systems. There are two types of engineering, forward engineering and reverse engineering. Forward engineering is the traditional process of moving from abstractions and logical designs to the physical implementation of a system.

Reverse engineering is the opposite of forward engineering. It takes an existing product, and creates a CAD model, for modification or reproduction to the design aspect of the product. It can also be defined as the process or duplicating an existing component by capturing the components physical dimensions. Reverse engineering is usually undertaken in order to redesign the system for better maintainability or to produce a copy of a system without access to the design from which it was originally produced.

Today's Reverse Engineering process basically includes two steps. At first digitize a physical part; at second 3D modeling the part from the digitized data. After editing models can be manufactured using Rapid Prototyping or CNC machining.
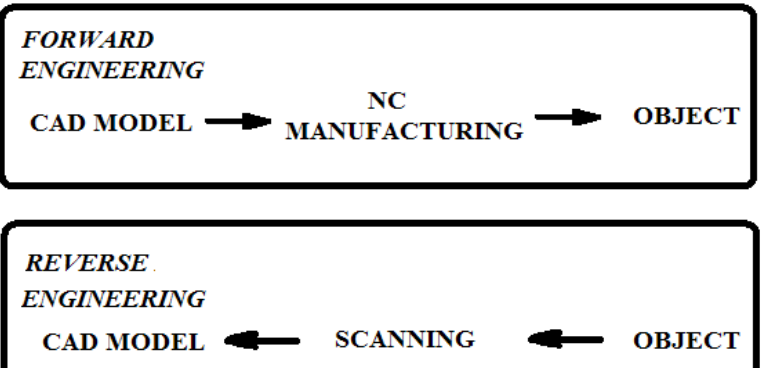

Fig. 1. Reverse and Forward engineering

Core and cavity parts for injection molding process and compression molding process are made directly from received dates quite often.
In present it exists more dimensional than 2D scans which has a lot of advantageous, on the other hand their price is higher than 2D. Here is the question to invest to new scanner or use appropriate software.

\section{EXPERIMENT}

Ceramic coffee cup was used for the scanning to keep of author's hand writing. For the receiving of three dimensional dates of physical part was used non-contact method with using laser probe Otimet which was fasten to Copy Mate CNC machine.

This combination guarantees receiving date in STL format. Optimet's probe emits laser beam on surface of product which scans surface of part.

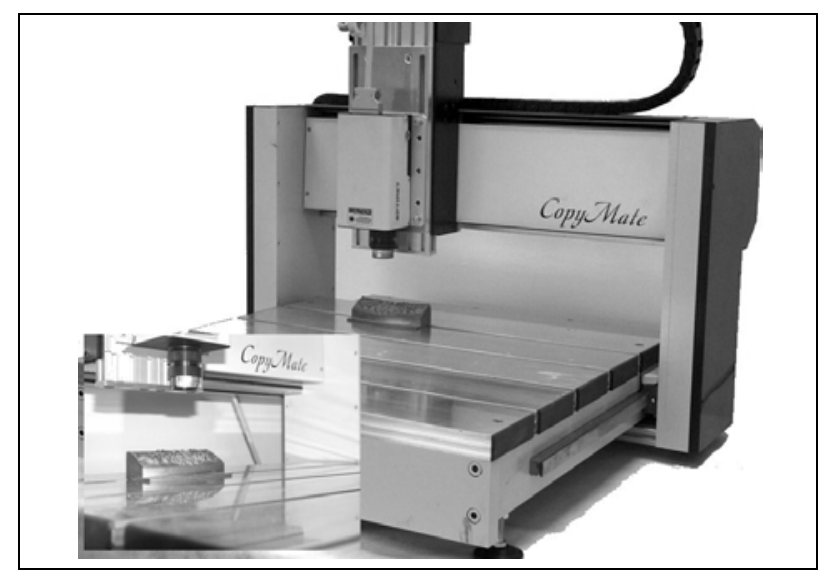

Fig. 2. CNC scanner Copy Mate with laser Otimet probe

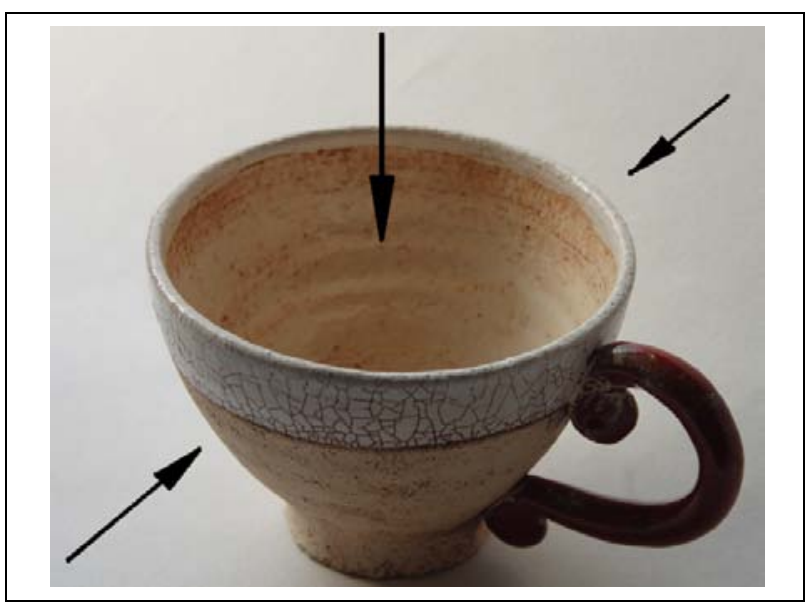

Fig. 3. Ceramic coffee cup with directions of scanning

Value of steps in axis $\mathrm{X}$ and $\mathrm{Y}$ have to be set at first. This value totally influences quality and time of scanning. Secondly scanned area is chosen by two opposite corners. Length 
between probe and the part had to be set at last in relation to quality and reflection. After that, cup was scanned from three different sides: front side, back side and top as it can be seen in Fig.3.

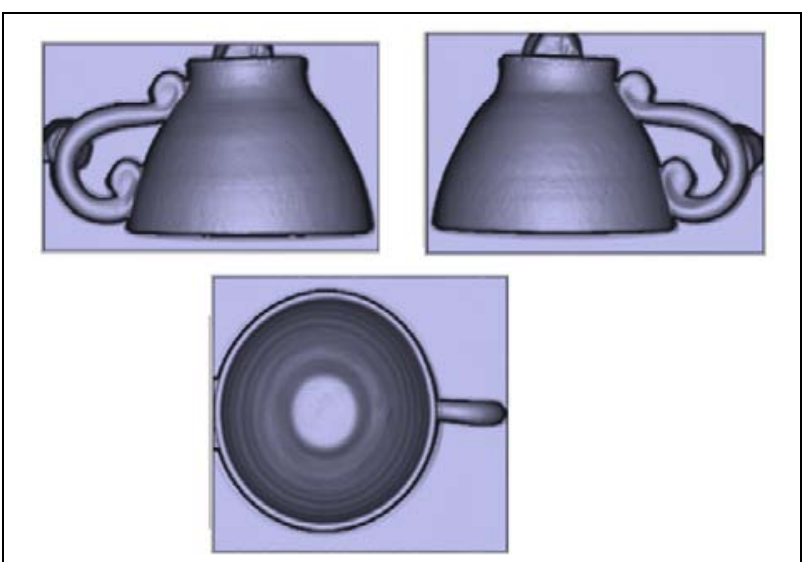

Fig. 4. Scanned part (*.stl)

For working with digitalized data software Catia V5R18 was used and for modifying of mesh Digitalized Shape Editor was used.

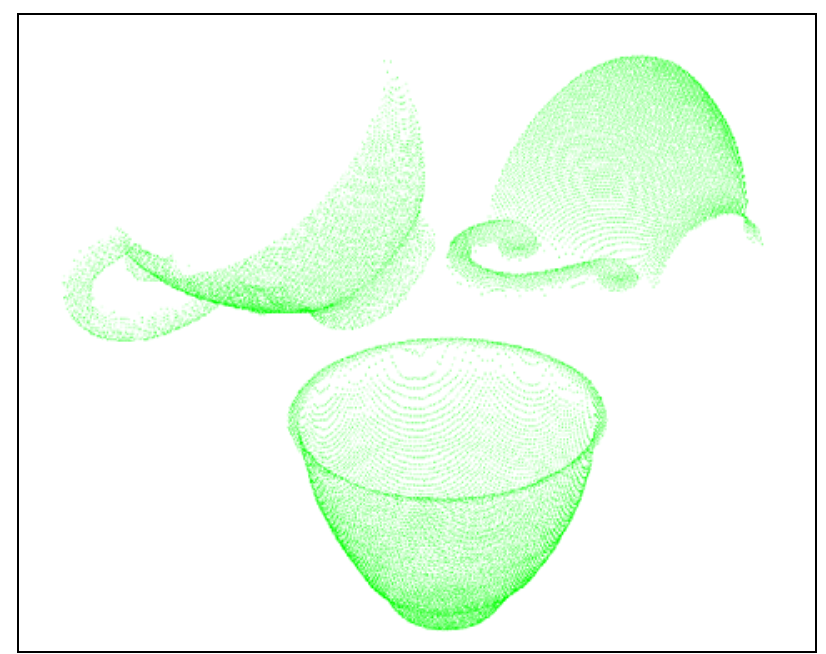

Fig. 5. Cloud of points (*.ascii)

Firstly three *.stl scans were imported to clouds of points (*ascii) where they were repaired, edited and unnecessary points was removed finally. Secondly each cloud of point was fixed to a right position. As can be seen in Fig. 5., there were fixed only right side, left side and top. Bottom was filled automatically by command Fill Hole.

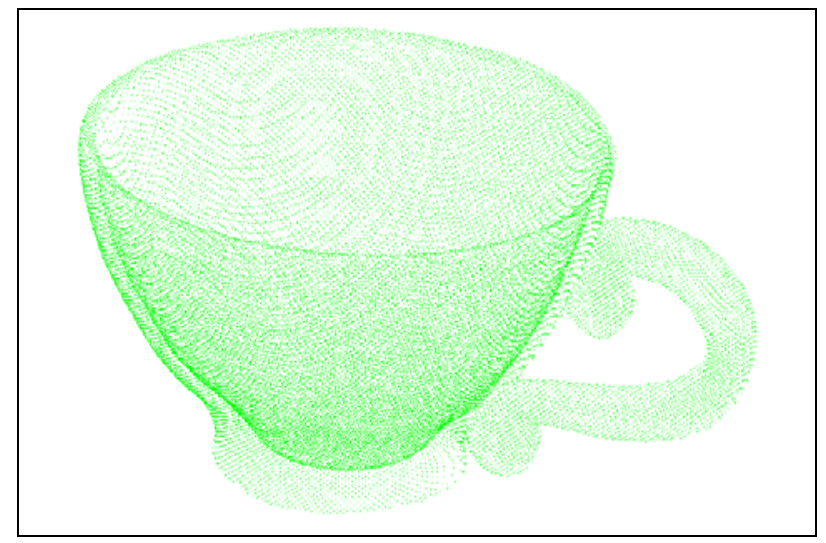

Fig. 6. Merged cloud of points

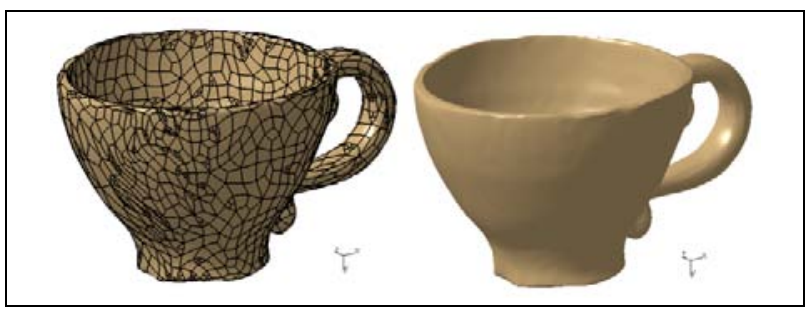

Fig. 7. Surface and body - finish part

At the two last steps surface is created by command Automatic Surface and body is created by command Close Surface in module Part Design as can be seen in Fig.7.

These fixed parts were merged to one cloud of points by the command Cloud Merge. After this step mesh could be made by the command Mesh Creation or can be finished manually with using Interactive Triangle Creation.

\section{CONCLUSION}

As it was told in abstract reverse engineering is good technology to duplicate objects which are already made. Sometimes for scanning easy parts are used needlessly more expensive scanners. Digitalized Shape Editor seems to be an interesting computational module which can not only improve the quality of scanned object and expedite the repairing of old or broken products when is used correctly, but also it can merge some clouds of points together. Sometime it can be happened that machine is not able to scan some parts of products (inside thread, negative draft, corners, etc.) due to end product is a body it is very easy to modify in Part Design module or in other ones.

\section{ACKNOWLEDGEMENTS}

This article is financially supported by the internal grant of TBU in Zlín No. IGA/10/FT/11/D funded from the resources of specific university research and by the European Regional Development Fund under the project CEBIA-Tech No. CZ.1.05/2.1.00/03.0089.

\section{REFERENCES}

Krumal, M.; Stanek, M.; Manas, M.; Manas, D.; Kyas, K. \& Cerny, J. (2010). Fluidity of Thermoplastic Elastomers, $D A A A M$, p. 1185, ISSN 1726-9679, ISBN 978-3-90150973-5, Zadar, Croatia

Kyas K.; Stanek M.; Manas M.; Manas D.; Krumal M. \& Cerny J. (2010). DAAAM, p. 1081, ISSN 1726-9679, ISBN 978-3901509-73-5, Zadar, Croatia

Manas, D.; Stanek, M.; Manas, M.; Pata V. \& Javorik, J. (2009). Influence of Mechanical Properties on Wear of Heavily Stressed Rubber Parts, KGK - Kautschuk Gummi Kunststoffe, 62. Jahrgang, , ISSN 0948-3276, p.240-245

Stanek, M.; Manas, D.; Manas, M.; Pata V.; Sanda, S.; Senkerik, V. \& Skrobak, A. (2011). How the Filler Influence the Fluidity of Polymer, Chemicke listy, Vol 105, ISSN 0009-2770, p.303-305

Stanek, M.; Manas, M.; Manas, D. \& Sanda, S. (2009). Plastics Parts Design Supported by Reverse Engineering and Rapid Prototyping, Chemicke listy, Vol 103, ISSN 0009-2770, pp.91-95

Stanek, M.; Manas, M.; Manas, D. \& Sanda, S. (2009). Influence of Surface Roughness on Fluidity of Thermoplastics Materials, Chemicke listy, Vol 103, ISSN 0009-2770, p.91-95 